OPEN ACCESS

Edited by:

Biao Zhao,

Zhengzhou University of Aeronautics,

China

Reviewed by:

Abu Zayed M. Saliqur Rahman,

The Ohio State University,

United States

Xiaomeng Fan,

Northwestern Polytechnical

University, China

*Correspondence:

Changwei Shao

chwshao@126.com

Yingde Wang

wangyingde@nudt.edu.cn

Specialty section:

This article was submitted to Polymeric and Composite Materials,

a section of the journal

Frontiers in Materials

Received: 20 May 2020 Accepted: 22 October 2020 Published: 24 November 2020

Citation:

Long $X$, Zhang S, Shao $C$, Wang $B$ and Wang $Y$ (2020) Effects of Heat-

Treatment on the Microstructure,

Electromagnetic Wave Absorbing

Properties, and Mechanical Properties

of SiCN Fibers.

Front. Mater. 7:563891.

doi: 10.3389/fmats.2020.563891

\section{Effects of Heat-Treatment on the Microstructure, Electromagnetic Wave Absorbing Properties, and Mechanical Properties of SiCN Fibers}

\author{
Xin Long, Shuai Zhang, Changwei Shao*, Bing Wang and Yingde Wang * \\ Science and Technology on Advanced Ceramic Fibers and Composites Laboratory, College of Aerospace Science and \\ Engineering, National University of Defense Technology, Changsha, China
}

SiCN fibers can not only be used for reinforcement of composites materials but also for electromagnetic wave (EMW) absorbing applications in a high-temperature oxidizing environment above $1,200^{\circ} \mathrm{C}$. In this work, the microstructural evolution and EMW absorbing properties of SiCN fibers after annealing at $1,300-1,600^{\circ} \mathrm{C}$ in $\mathrm{N}_{2}$ atmosphere were investigated. Results showed that the amorphous SiCN fibers presented poor EMW absorbing properties when the annealing temperature was below $1,400^{\circ} \mathrm{C}$. As the annealing temperature increased to $1,500^{\circ} \mathrm{C}$, the $\mathrm{EMW}$ absorbing properties could been largely enhanced with a minimum reflation loss value of $-55.8 \mathrm{~dB}$ and an effective absorption bandwidth value of $2.5 \mathrm{GHz}$. The enhanced EMW absorbing properties should contribute to the formation and growth of grain boundaries and defects among the amorphous fiber matrix and turbostratic graphite carbon, which could enhance the space charge polarization at the heterogeneous interfaces and increase the conductivity of the SiCN fibers. Meanwhile, SiCN fibers retained a rather high tensile strength of $\sim 1.0 \mathrm{GPa}$ after annealing at $1,500^{\circ} \mathrm{C}$, which showed it to be a promising candidate for reinforcing the stealth ceramic matrix composites used in harsh environments.

Keywords: SiCN fibers, microstructural evolution, dielectric properties, electromagnetic wave absorbing, high temperature

\section{INTRODUCTION}

Polymer-derived ceramics, such as $\mathrm{SiC}, \mathrm{SiCN}$, and $\mathrm{SiBCN}$, are considered as superior electromagnetic wave (EMW) absorbers that can be used in a high-temperature oxidizing environment above $1,200^{\circ} \mathrm{C}$, due to their excellent high-temperature performance and adjustable semiconducting properties (Duan et al., 2016; Storch et al., 2018). Among them, a polymer-derived ceramic with a fiber morphology could be used as reinforcement for the preparation of ceramic matrix composites, showing more practical significance in structural/functional applications at high temperatures.

Several works have studied the EMW absorbing properties of commercial ceramic fibers derived from pre-ceramic polymers. For example, Mo et al. (2017) found that heat treatment could improve the EMW absorbing properties of amorphous $\mathrm{SiC}$ fibers (Tyranno ZMI) due to the growth of $\mathrm{SiC}$ nanocrystals. Ding and coworkers compared the EMW absorbing properties of Nicalon-202 and KD-I $\mathrm{SiC}$ fibers, showing that KD-I fibers with more free carbon presented better EMW absorption (Ding 
et al., 2011). However, at present, almost all of the available SiC fibers have shown poor EMW absorbing properties with a very large reflection loss $(\mathrm{RL})$ value $(>-10 \mathrm{~dB})$ due to the impedance mismatch. When nitrogen was introduced into the SiC fibers, the impedance match could be improved (Long et al., 2019a). These nitrogen-doped fibers are also called SiCN fibers.

Although SiCN fibers show excellent impedance matching behavior, the EMW absorbing properties are usually poor when $\mathrm{SiCN}$ fibers consist of only one amorphous $\mathrm{SiCN}$ phase with very few high-dielectric nanocrystals (Widgeon et al., 2012; Ye et al., 2013). Nowadays, several studies have introduced high-dielectric nanocrystals (such as carbon nanotubes and graphene) into amorphous $\mathrm{SiCN}$ ceramics by chemically modifying the preceramic polymer and finally improving the EMW absorbing properties (Liu et al., 2017a; Liu et al., 2017b). Another method includes simply heat treating the amorphous SiCN ceramics with different pyrolysis atmospheres or temperatures, where the nano-SiC and free carbon nanodomains could form insitu (Gian et al., 2020). However, although great effort has been devoted to SiCN ceramics in the morphology of bulk and powder, few attempts have been made to improve the EMW absorbing properties of SiCN fibers.

In this work, turbostratic graphite carbon was formed in-situ in the amorphous SiCN fibers by simply heat treating them at $1,300^{\circ} \mathrm{C}-1,600^{\circ} \mathrm{C}$ in an $\mathrm{N}_{2}$ atmosphere. Results showed that the EMW absorbing properties of the amorphous SiCN fibers could be largely enhanced after annealing at $1,500^{\circ} \mathrm{C}$, with a minimum $\mathrm{RL}$ value of $-55.8 \mathrm{~dB}$ and an effective absorption bandwidth (EAB) value of $2.5 \mathrm{GHz}$. The probable EMW absorbing mechanism was proposed in this work. The microstructural evolution and mechanical properties of the SiCN fibers after annealing at different high temperatures were also investigated in detail.

\section{EXPERIMENTAL SECTION}

\section{Materials}

SiCN fibers were prepared according to our previous work by using electron beams curing polycarbosilane (EB-PCS) fibers as starting precursors (Long et al., 2019b). The used $\mathrm{N}_{2}$ gas (Xiangfeng Co. Ltd., China) was of high purity (>99.99\%).

\section{High-Temperature Annealing}

SiCN fibers were treated in a graphite furnace at a temperature range of $1,300^{\circ} \mathrm{C}-1,600^{\circ} \mathrm{C}$ in an $\mathrm{N}_{2}$ atmosphere with a heating rate of $5^{\circ} \mathrm{C} / \mathrm{min}$. After holding for $1 \mathrm{~h}$ at the target temperature, the fibers were furnace cooled to room temperature.

\section{Characterization}

The carbon content of the obtained SiCN fibers was measured by a Horiba carbon/sulfur analyzer EMIA-320V (Horiba, Japan). The oxygen and nitrogen content was determined by a Horiba oxygen/nitrogen analyzer EMIA-820 (Horiba, Japan). The content of silicon in the samples was calculated by the subtraction method using the percentage weight. Raman spectra were recorded by a micro-Raman spectrometer Horiba
HR800 (Horiba, Japan) with an Ar-Ion laser wavelength of $514.5 \mathrm{~nm}$ and Raman shift range of $800-2,000 \mathrm{~cm}^{-1}$. X-ray diffraction studies were carried out with a Bruker AXS D8 Advance diffractometer (Bruker, Germany) with $\mathrm{Cu} \mathrm{Ka}$ radiation $\left(\mathrm{k}=1.54178 \mathrm{~A}^{\circ}\right)$ and a scanning speed of $0.0167^{\circ}$ / s. The fiber morphology was observed by a HITACHI S- 4800 scanning electron microscope (SEM, Japan). Transmission electron microscopy (TEM) analysis was carried out by Titan G2 60-300 with image corrector. Before observing with TEM, the fibers were grinded into powder and dispersed in alcohol by ultrasonication for $10 \mathrm{~min}$, which was followed by depositing a drop of the dispersed solution on a $3 \mathrm{~mm}$ carbon-coated copper grid. For obtaining the relative complex permittivity of the SiCN fibers, 65 vol\% fibers and 35 vol\% epoxy were mixed by stirring with glass blocks for $10 \mathrm{~min}$ in a flask, then homogeneous fiber prepreg could be prepared, which was followed by a hotpress process at $130^{\circ} \mathrm{C}$ with $1 \mathrm{MPa}$. The obtained composite samples with the sizes of $22.86 \times 10.16 \times 3.0 \mathrm{~mm}$ and $15.8 \times$ $7.9 \times 3.0 \mathrm{~mm}$ were measured by a vector network analyzer (Agilent N5230A, America) in the range of 8-12 and $12-18 \mathrm{GHz}$, respectively. The relative complex permittivity of the SiCN fibers were calculated using the logarithmic law of mixing:

$$
\ln \varepsilon=V_{f} \ln \varepsilon_{f}+V_{m} \ln \varepsilon_{m}
$$

where $\varepsilon, \varepsilon_{f}$, and $\varepsilon_{m}$ are the complex permittivity of composite samples, SiCN fibers, and epoxy matrix, respectively; $V_{f}$ and $V_{m}$ are the volume fraction of the SiCN fibers and epoxy matrix, respectively. The tensile strength and Young's modulus of SiCN fibers with $25 \mathrm{~mm}$ length was measured at room temperature using a universal strength machine (Testometric Micro 350, United Kingdom) with a load cell of $5 \mathrm{~N}$ and a crosshead speed of $5 \mathrm{~mm} / \mathrm{min}$. Each tensile strength data point was the average of 24 monofilaments.

\section{RESULTS AND DISCUSSION}

\section{Composition and Microstructure of SiCN Fibers With Different Annealing Temperatures}

The chemical composition of SiCN fibers with different annealing temperatures are shown in Table 1. It can be clearly seen that, the nitrogen content of the SiCN fibers decreased obviously while the carbon content increased with the annealing temperature increase, which finally caused the $\mathrm{C} / \mathrm{N}$ atomic ratio to increase from 0.60 to 1.95 when the annealing temperature reached up to $1,600^{\circ} \mathrm{C}$. The decreasing of the nitrogen content indicated the carbothermal reduction between the $\mathrm{Si}_{3} \mathrm{~N}_{4}$ phase and free carbon (Eq. 2), which are the two major phases in the polymer-derived SiCN fibers (Mera et al., 2009; Prasad et al., 2012).

$$
\mathrm{Si}_{3} \mathrm{~N}_{4}(\mathrm{am})+3 \mathrm{C}(\mathrm{s})=3 \mathrm{SiC}(\mathrm{s})+2 \mathrm{~N}_{2}(\mathrm{~g})
$$


TABLE 1 | Chemical composition of SiCN fibers with different annealing temperatures.

\begin{tabular}{|c|c|c|c|c|c|c|c|}
\hline \multirow[t]{2}{*}{ Samples } & \multirow[t]{2}{*}{ Annealing temperatures $\left({ }^{\circ} \mathrm{C}\right)$} & \multicolumn{4}{|c|}{ Chemical composition (wt\%) } & \multirow[t]{2}{*}{$\mathrm{C} / \mathrm{N}$ ratio } & \multirow[t]{2}{*}{ Formula } \\
\hline & & Si & C & $\mathbf{N}$ & 0 & & \\
\hline SCN-1,300 & 1,300 & 51.6 & 15.7 & 30.5 & 2.17 & 0.60 & $\mathrm{SiC}_{0.71} \mathrm{~N}_{1.18} \mathrm{O}_{0.07}$ \\
\hline SCN-1,400 & 1,400 & 56.9 & 15.5 & 25.8 & 1.78 & 0.70 & $\mathrm{SiC}_{0.64} \mathrm{~N}_{0.91} \mathrm{O}_{0.05}$ \\
\hline SCN-1,500 & 1,500 & 56.0 & 23.6 & 19.1 & 1.25 & 1.44 & $\mathrm{SiC}_{0.98} \mathrm{~N}_{0.68} \mathrm{O}_{0.04}$ \\
\hline SCN-1,600 & 1,600 & 60.3 & 24.1 & 14.4 & 1.15 & 1.95 & $\mathrm{SiC}_{0.93} \mathrm{~N}_{0.48} \mathrm{O}_{0.03}$ \\
\hline
\end{tabular}

The carbothermal reduction between the $\mathrm{Si}_{3} \mathrm{~N}_{4}$ phase and free carbon caused the consumption of free carbon, which could be observed from the Raman spectra (Figures 1A). All of the SiCN fibers with different annealing temperatures showed a $G$ band peak at $\sim 1,600 \mathrm{~cm}^{-1}$ relative to the breathing mode of $\mathrm{sp}^{2}$ carbon and a $\mathrm{D}$ band peak at $\sim 1,300 \mathrm{~cm}^{-1}$ relative to the in-plane bond stretching of $\mathrm{sp}^{2}$-hybridized carbon (Mera et al., 2009; Chen et al., 2014). As the annealing temperature increased, the intensity of all of the Raman peaks decreased, which indicated the consumption of free carbon via the carbothermal reduction between the $\mathrm{Si}_{3} \mathrm{~N}_{4}$ phase and free carbon, as a result, causing the release of nitrogen gas. Thus, the Raman spectra agreed well with the chemical composition results. For further quantitative analysis, the Raman spectra, the G band, and D band were curve-fitting with a Breit-Wigner-Fano function and Lorentzian equation, respectively. The obtained $\mathrm{I}_{\mathrm{D}} / \mathrm{I}_{\mathrm{G}}$ intensity ratios derived from the curve-fitting results could be used to calculate the average size of the free carbon nanoclusters $\left(L_{\mathrm{a}}\right)$ with a Ferrari-Robertson equation (Zickler et al., 2006). When the free carbon nanoclusters showed a two-dimension (2D) grain growth process at a high temperature, the $L_{\mathrm{a}}$ could be calculated by Eq. 3, where $k$ is the pre-exponential factor, $R$ is the Molar gas constant, $G^{*}$ is the activation energy, and $T$ is the annealing temperature (Chen et al., 2014). The logarithm of the two sides of Eq. 3 could obtain Eq. 4, indicating the $\ln \left(\mathrm{L}_{a}^{2}\right)$ and $1 / \mathrm{T}$ may satisfy the liner relationship. Figures 1B shows the plots of $\ln \left(\mathrm{L}_{a}^{2}\right)$ vs. 1,000/T. The results showed that the $L_{\mathrm{a}}$ value decreased slightly when the annealing temperature increased from $1,300^{\circ} \mathrm{C}$ to $1,400^{\circ} \mathrm{C}$, which could have contributed to the graphitization of amorphous free carbon to form turbostratic graphite carbon (Sarkar et al., 2011). As the annealing temperature increased to above $1,400^{\circ} \mathrm{C}$, the $L_{\mathrm{a}}$ value increased obviously, and the $\ln \left(\left(\mathrm{L}_{a}^{2}\right)\right)$ vs. $1 / T$ well met the liner relationship at the temperature range of $1,400^{\circ} \mathrm{C}-1,600^{\circ} \mathrm{C}$. Thus, turbostratic graphite carbon in the $\mathrm{SiCN}$ fibers showed a $2 \mathrm{D}$ grain growth process at the temperature range of $1,400^{\circ} \mathrm{C}-1,600^{\circ} \mathrm{C}$. The slope from the fitted liner curing is relative to the activation energy $G^{*}$ for the growth of the turbostratic graphite carbon, and the value is $82 \mathrm{~kJ} / \mathrm{mol}$.

$$
\begin{gathered}
L_{a}^{2}=k \exp \left(\frac{-G^{*}}{R T}\right) \\
\ln \left(L_{a}^{2}\right)=-\frac{G^{*}}{R} \times \frac{1}{T}+\text { constant }
\end{gathered}
$$

Figure 2 shows the X-ray diffraction patterns of SiCN fibers after annealing at different temperatures. When the annealing temperature was below $1,500^{\circ} \mathrm{C}$, the $\mathrm{SiCN}$ fibers could remain completely amorphous without diffraction peaks detected. As the annealing temperature increased up to $1,600^{\circ} \mathrm{C}$, three obvious diffraction peaks at $2 \theta=35.60^{\circ}, 59.98^{\circ}$, and $71.78^{\circ}$ could be observed, indicating the formation of a $\beta$-SiC (JPCDS \#29-1129) phase. It is believed that these $\beta-\mathrm{SiC}$ phases were likely formed in-situ from the production of the carbothermal reduction between
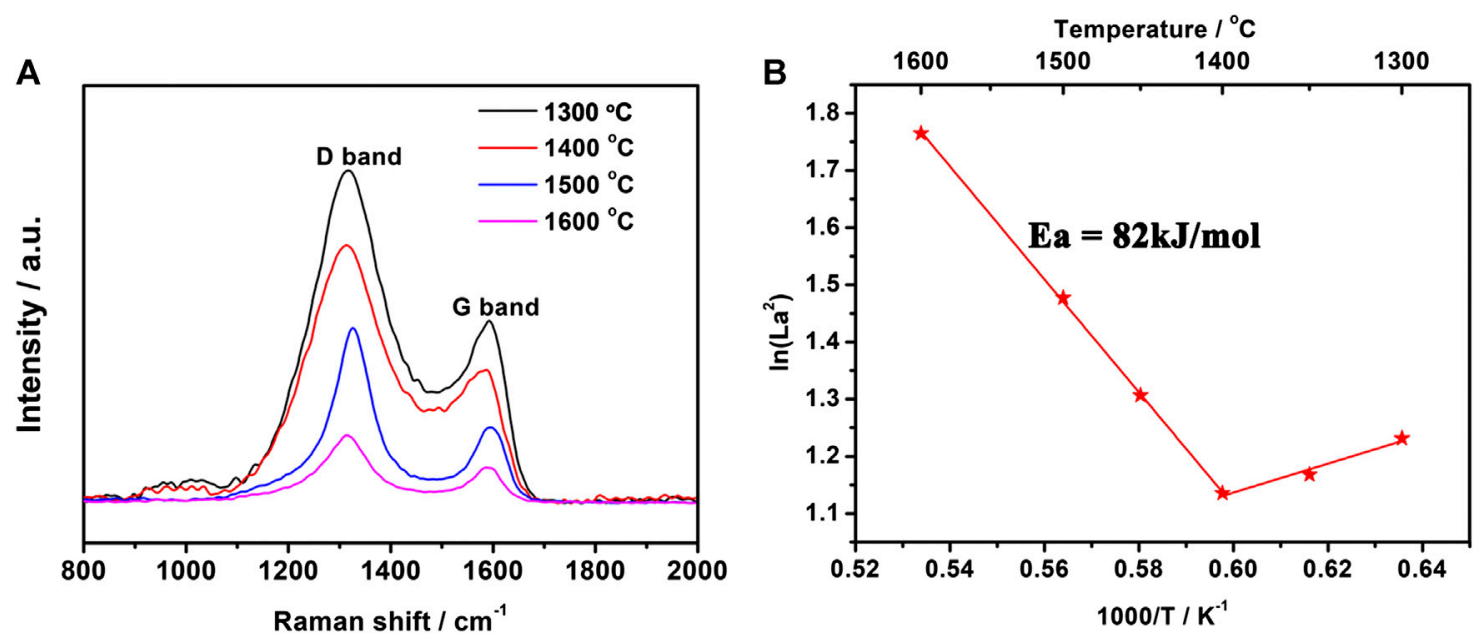

FIGURE 1 | Raman spectra of SiCN fibers after annealing at different temperatures (A); the plots of $L_{a}$ Vs. $1,000 / T$ (B) 


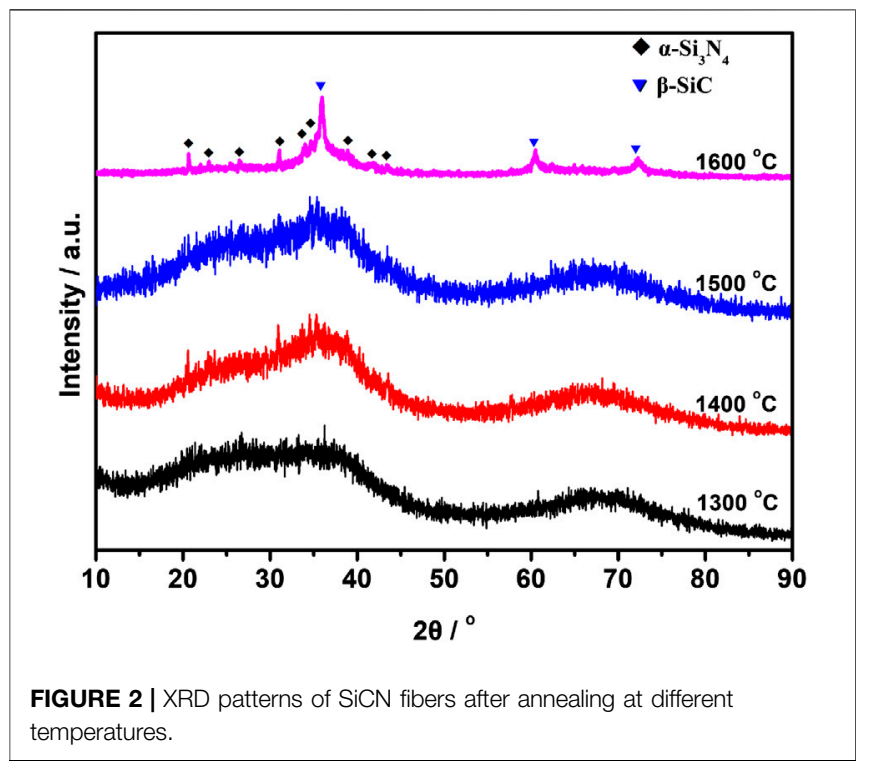

the $\mathrm{Si}_{3} \mathrm{~N}_{4}$ phase and free carbon. Meanwhile, weak diffraction peaks related to the $\alpha-\mathrm{Si}_{3} \mathrm{~N}_{4}$ (JPCDS \#09-0250) phase could also be detected. The formation of a crystalline phase may have increased the amount of grain boundary, and finally caused the increase of the dielectric constant as a result.

To further understand the microstructure of SiCN fibers after annealing at different temperatures, TEM micrographs were obtained, as shown in Figure 3. It can be seen that SCN-1,300 showed a totally amorphous microstructure. As the annealing temperature increased to $1,400^{\circ} \mathrm{C}$, a small amount of turbostratic graphite carbon with 2-3 layers could be observed in SCN-1,400, while the fibers were still a fully amorphous micromorphology. The turbostratic graphite carbon grew to more than three layers when the annealing temperature increased to $1,500^{\circ} \mathrm{C}$, and further grew as the annealing temperature went up to $1,600^{\circ} \mathrm{C}$. Meanwhile, a small amount of $\mathrm{Si}_{3} \mathrm{~N}_{4}$ grains with interplanar spacing of $0.27 \mathrm{~nm}$ could also be detected in SCN-1,600. These results agreed well with the quantitative analysis of the Raman spectra, and also showed the graphitization of amorphous free carbon at $1,400^{\circ} \mathrm{C}$
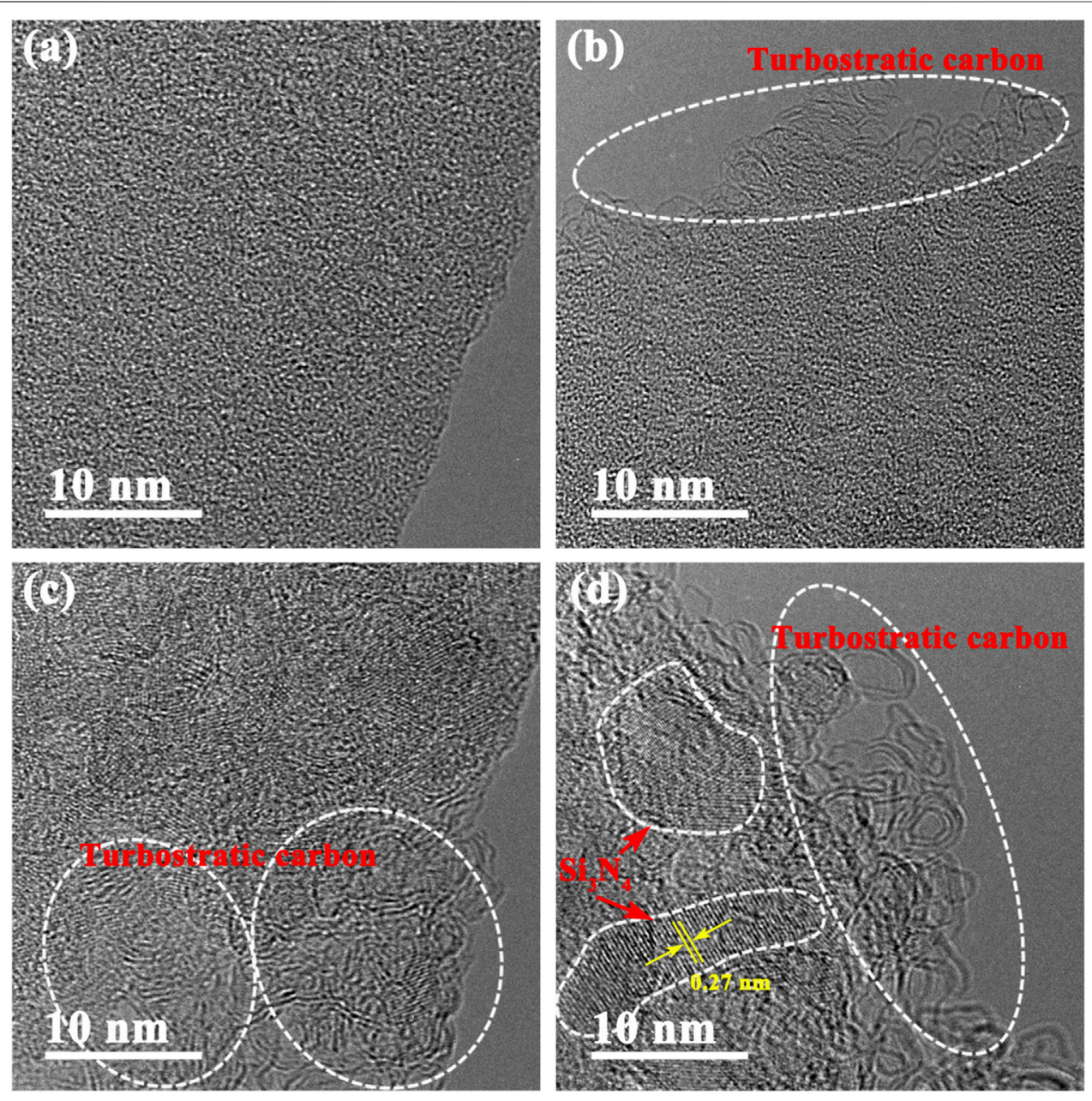

FIGURE 3 | TEM micrographs of SiCN fibers after annealing at different temperatures: SCN-1,300 (A), SCN-1,400 (B), SCN-1,500 (C), and SCN-1,600 (D). 

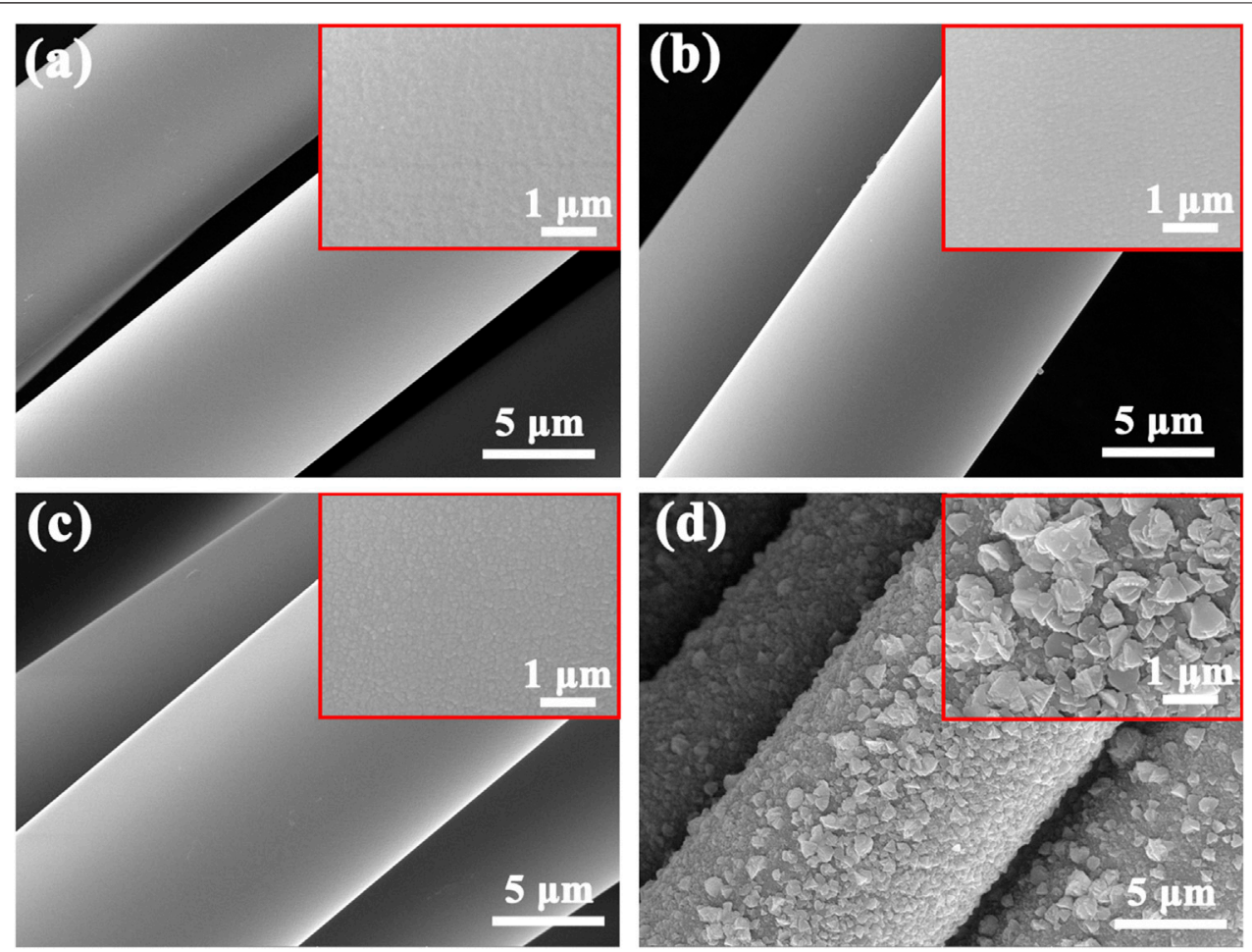

FIGURE 4 | SEM micrographs of SiCN fibers after annealing at different temperatures: SCN-1,300 (A), SCN-1,400 (B), SCN-1,500 (C) and SCN-1,600 (D).

and the growth of turbostratic graphite carbon at above $1,400^{\circ} \mathrm{C}$. The formation and growth of turbostratic graphite carbon could increase the amount of grain boundaries and defects among the fiber matrix and free carbon, which could lead to the enhancement of space charge polarization and interface polarization, thus, consequently, improving the EMW absorbing properties of the SiCN fibers.

Figure 4 shows the scanning electron microscope micrographs of $\mathrm{SiCN}$ fibers with different annealing temperatures. These SiCN fibers showed a rather smooth surface when the annealing temperature was below $1,500^{\circ} \mathrm{C}$. Very fine nanograins with a size of $50 \mathrm{~nm}$ could be formed on the fiber surface when the annealing temperature reached $1,500^{\circ} \mathrm{C}$. Considering that a sharp decrease of nitrogen content was detected at $1,500^{\circ} \mathrm{C}$, the nanograins were likely formed in the in-situ $\mathrm{SiC}$ phase via the carbothermal reduction between the $\mathrm{Si}_{3} \mathrm{~N}_{4}$ phase and free carbon. The size of these in-situ-formed $\mathrm{SiC}$ nanograins could grow up to near $1 \mu \mathrm{m}$ as the annealing temperature went up to $1,600^{\circ} \mathrm{C}$, indicating the enhancement of the carbothermal reduction between the $\mathrm{Si}_{3} \mathrm{~N}_{4}$ phase and free carbon. Thus, SCN1,600 showed a very rough surface, which is harmful for the retention of tensile strength.

\section{Dielectric and Electromagnetic Wave Absorbing Properties of SiCN Fibers After Annealing at Different Temperatures}

The relative complex permittivity $\left(\varepsilon=\varepsilon^{\prime}-j \varepsilon^{\prime \prime}\right)$ is very important for the EMW absorbing properties of SiCN fibers. The real part $\left(\varepsilon^{\prime}\right)$ can present the storage ability of EMW energy, while the imaginary part $\left(\varepsilon^{\prime \prime}\right)$ is related to the loss ability of EMW energy (Li et al., 2019). Thus, a rather high $\varepsilon$ " is necessary for SiCN fibers to show excellent EMW absorbing properties. Figure 5 shows the real part $\left(\varepsilon^{\prime}\right)$ and imaginary part $\left(\varepsilon^{\prime \prime}\right)$ as well as the dielectric loss $\left(\tan \delta=\varepsilon^{\prime \prime} / \mathcal{\varepsilon}^{\prime}\right)$ at the frequency range of $8-18 \mathrm{GHz}$ for SiCN fibers with different annealing temperatures. SCN-1,300 and SCN1,400 showed similar $\mathcal{E}^{\prime}$ values of 9.0-10.1 during the whole testing frequency range. As the annealing temperature increased to $1,500^{\circ} \mathrm{C}$, the $\varepsilon^{\prime}$ values obviously increased to 9.8-13.7 and sharply increased to 16.9-23.1 when the annealing temperature reached $1,600^{\circ} \mathrm{C}$. Based on our previous analysis, it is believed that the consumption of the $\mathrm{Si}_{3} \mathrm{~N}_{4}$ phase (with $\varepsilon^{\prime}$ and $\varepsilon^{\prime \prime}$ values of $<9$ and $<0.1$, respectively) via the the carbothermal reduction with free carbon could finally cause the increase of the $\varepsilon^{\prime}$ and $\varepsilon^{\prime \prime}$ values according to the logarithmic law of mixing (Zhao et al., 2016). Meanwhile, the formation and growth of turbostratic graphite carbon may also cause the increase of the $\varepsilon^{\prime}$ and $\varepsilon^{\prime \prime}$ values due to the enhancement of space charge polarization and interface polarization when large amounts of grain boundaries and defects among the fiber matrix and free carbon were formed.

Based on the metal back panel model, the RL values of the $\mathrm{SiCN}$ fibers with different sample thicknesses at the frequency range of $8-18 \mathrm{GHz}$ could be calculated with Eq. 5 and Eq. 6 . Where $\varepsilon_{\mathrm{r}}, \mu_{\mathrm{r}}, Z_{\text {in }}$, and $Z_{0}$ are the permittivity, permeability, input impedance, and free-space impedance of the sample, respectively; and $c, d$, and $f$ represent the speed of light in vacuum, thickness of 

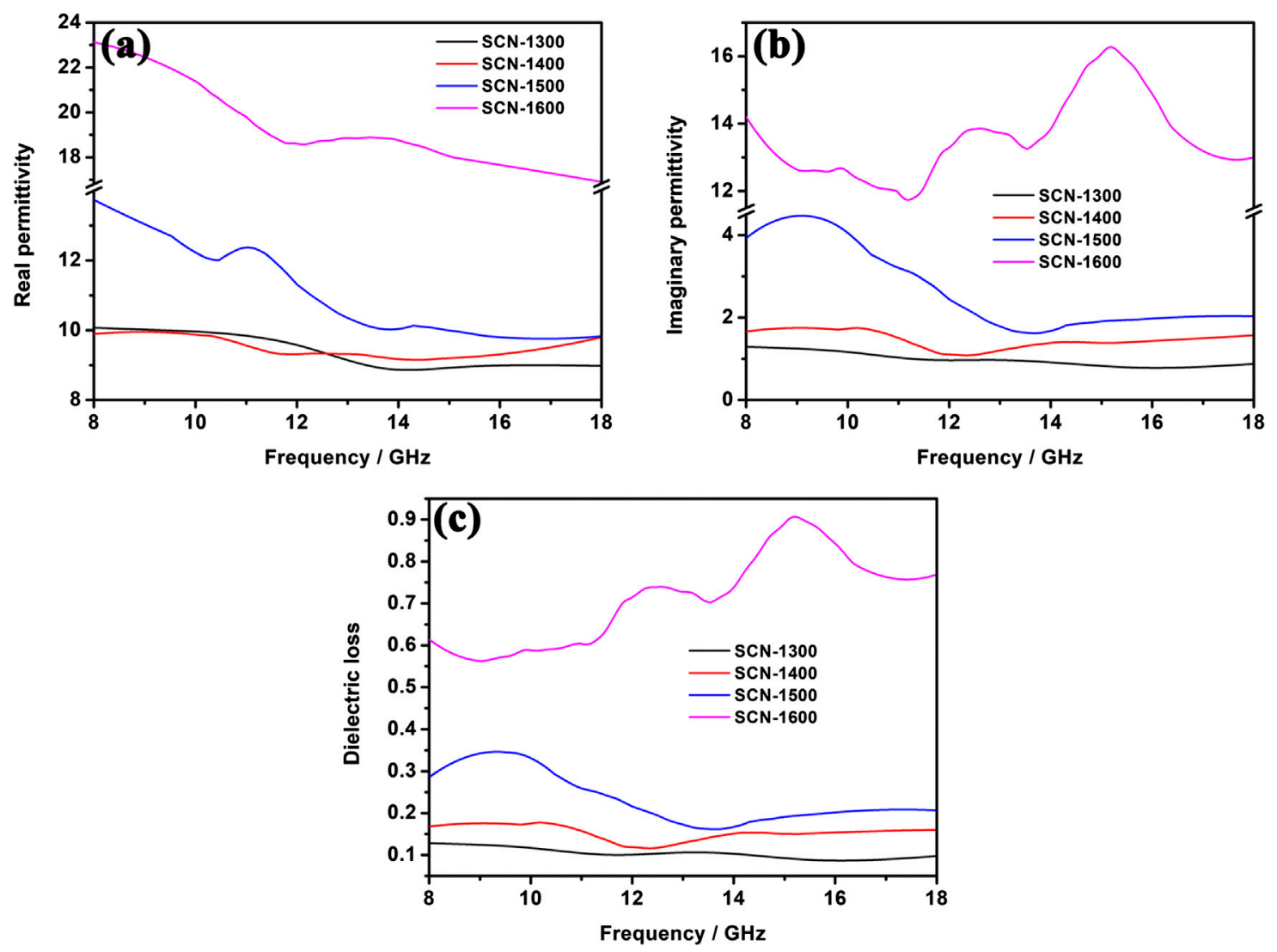

FIGURE $\mathbf{5}$ | The real (A) and imaginary (B) part of permittivity as well as the dielectric loss (C) at the frequency range of 8-18 GHz for SiCN fibers with different annealing temperatures.

the sample, and the microwave frequency, respectively. When the $\mathrm{RL}$ values are below $-10 \mathrm{~dB}$, it means more than $90 \%$ EMW energy could be absorbed, then the frequency range with $\mathrm{RL}$ values below $-10 \mathrm{~dB}$ is called an $\mathrm{EAB}$, which is also a very important parameter to evaluate the EMW absorbing properties of $\mathrm{SiCN}$ fibers.

Figure 6 shows the three-dimensional plots of the RL values vs frequency and thickness for SiCN fibers with different annealing temperatures. SCN-13,00 shows rather poor EMW absorbing properties with the minimum $\mathrm{RL}$ values of $-13.1 \mathrm{~dB}$ at $15.1 \mathrm{GHz}$ with a sample thickness of $5.0 \mathrm{~mm}$ and a narrow $\mathrm{EAB}$ of $0.8 \mathrm{GHz}$. After annealing at $1,400^{\circ} \mathrm{C}$, the EMW absorbing properties of SCN-1,400 could be improved with the minimum RL values of $-33.7 \mathrm{~dB}$ at $15.2 \mathrm{GHz}$ with a sample thickness of $4.9 \mathrm{~mm}$ and a wider EAB of $1.5 \mathrm{GHz}$. The EMW absorbing properties could be further improved as the annealing temperature reached $1,500^{\circ} \mathrm{C}$, when the minimum RL values could reach $-55.8 \mathrm{~dB}$ at $9.3 \mathrm{GHz}$ with a sample thickness of $2.3 \mathrm{~mm}$ and the $\mathrm{EAB}$ could reach a wider value of $2.5 \mathrm{GHz}$. According to the microstructure evolution analysis, the improvement of the EMW absorbing properties of SiCN fibers is consistent with the formation and growth of turbostratic graphite carbon. Thus, it is believed that the formation and growth of turbostratic graphite could form grain boundaries and defects among the amorphous fiber matrix and free carbon, which could enhance the space charge polarization at the heterogeneous interfaces and finally transform EMW energy into heat (Figure 7). Meanwhile, turbostratic graphite shows higher conductivity than amorphous free carbon, which could more easily absorb incident EMW through the forming current flow. However, when the annealing temperature reached $1,600^{\circ} \mathrm{C}$, the EMW absorbing properties of the SiCN fibers become very poor with a minimum RL values of $-9.1 \mathrm{~dB}$, which contributed to the impedance mismatch as most of the $\mathrm{Si}_{3} \mathrm{~N}_{4}$ phase was consumed via the carbothermal reduction after annealing at $1,600^{\circ} \mathrm{C}$.

$$
\begin{gathered}
\mathrm{RL}=20 \log _{10}\left|\frac{Z_{\text {in }}-Z_{0}}{Z_{\text {in }}+Z_{0}}\right| \\
Z_{\text {in }}=Z_{0}\left(\mu_{r} / \varepsilon_{r}\right)^{1 / 2} \tanh \left[j(2 \pi f d / c)\left(\mu_{r} / \varepsilon_{r}\right)^{1 / 2}\right]
\end{gathered}
$$

\section{Mechanical Properties of SiCN Fibers at a High Temperature}

Comparing with other Si-based ceramics for EMW absorbing applications, $\mathrm{SiCN}$ fibers present excellent mechanical properties 

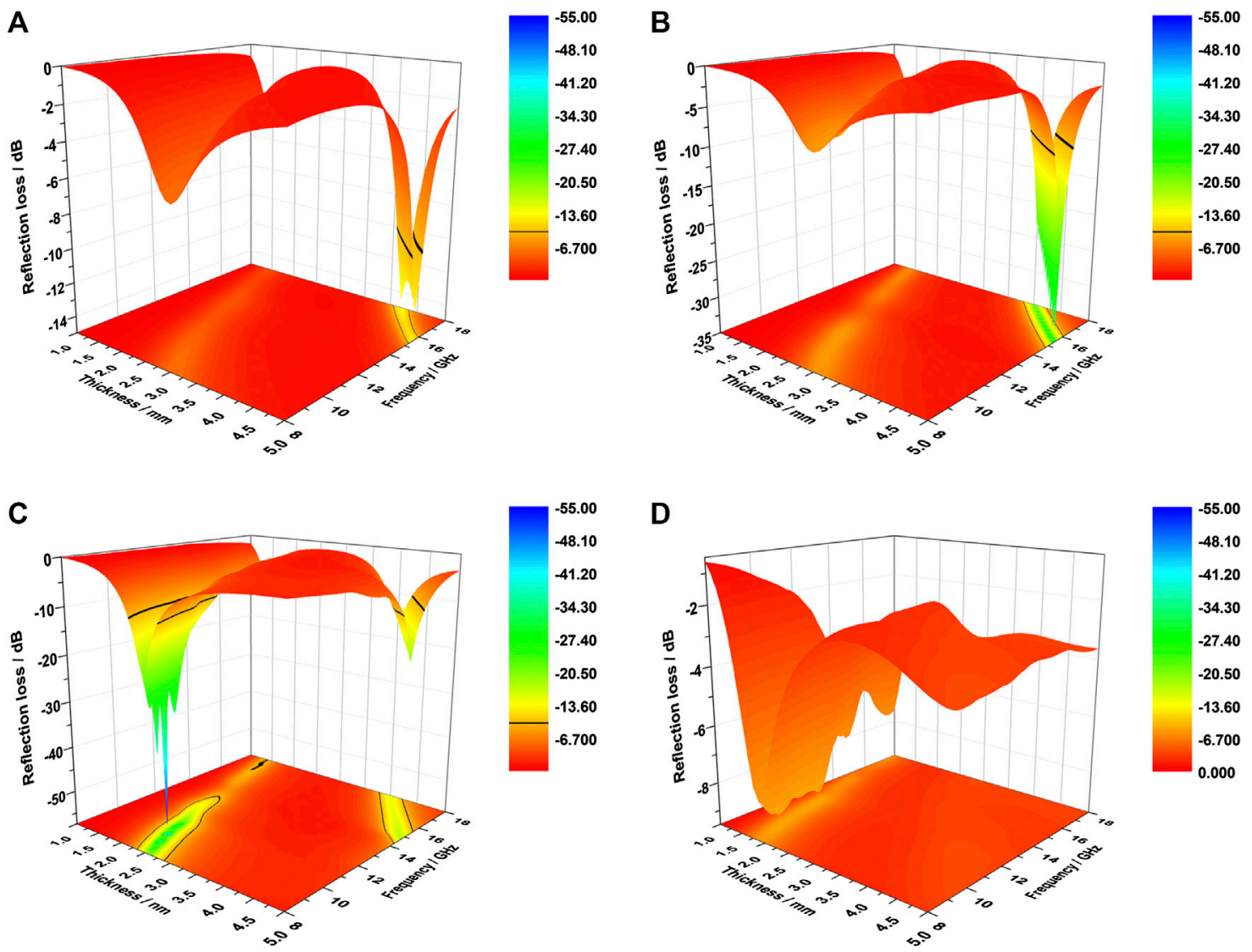

FIGURE 6 | Three-dimensional plots of the RL values vs frequency and thickness: SCN-1,300 (A), SCN-1,400 (B), SCN-1,500 (C), and SCN-1,600 (D).

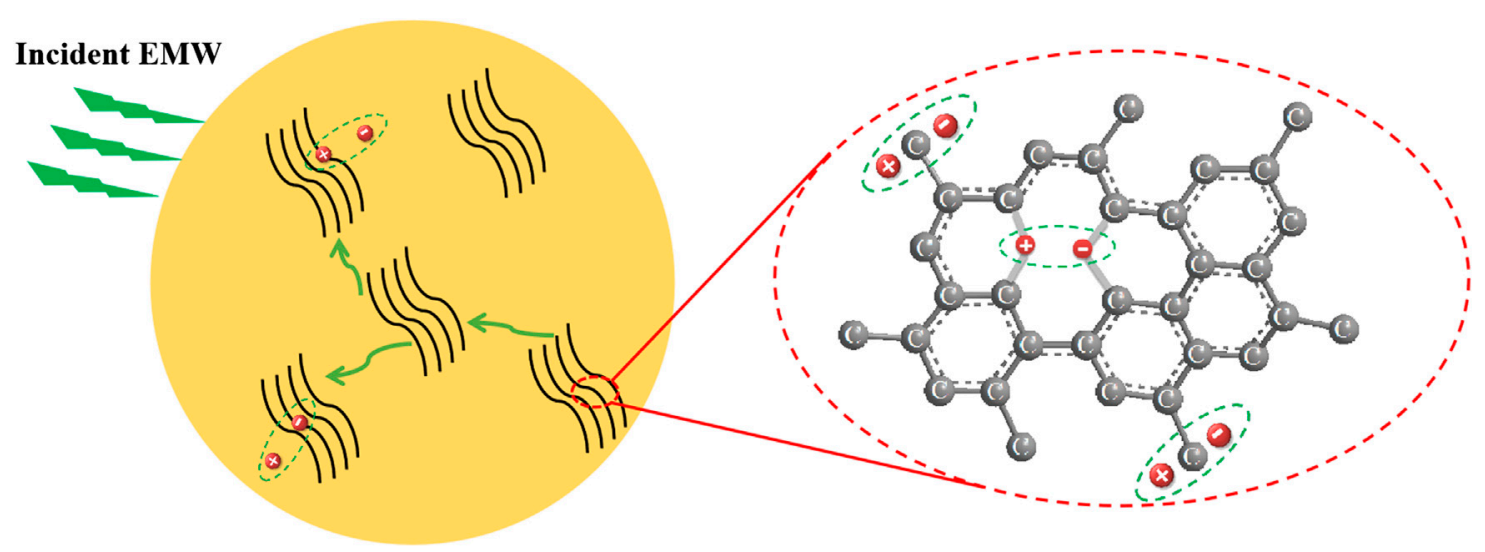

SiCN matrix $\quad$ W Turbostratic graphite Current flow

FIGURE 7 | Schematic diagram of the proposed mechanism for EMW absorption.

thus can meet the shortage of reinforcements for stealth ceramic matrix composites. Figure $\mathbf{8}$ shows the tensile strength and Young's modulus of SiCN fibers after annealing at different temperatures. The $\mathrm{SiCN}$ fibers could retain their tensile strength when the annealing temperature was below $1,400^{\circ} \mathrm{C}$. As the annealing temperature went up to $1,500^{\circ} \mathrm{C}$, the tensile strength obviously decreased to $\sim 1.0 \mathrm{GPa}$, and lost its tensile strength when the annealing temperature reached $1,600^{\circ} \mathrm{C}$. Thus, 


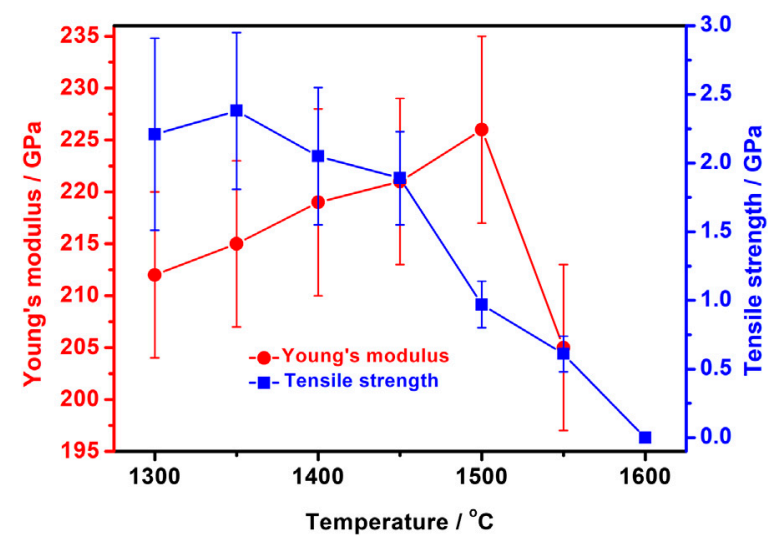

FIGURE 8 | The Young's modulus and tensile strength of SiCN fibers after annealing at high temperatures.

although the high-temperature treatment could enhance the EMW absorbing properties of the SiCN fibers, it could also cause a decrease of tensile strength. According to the previous analysis, $\mathrm{SiCN}$ fibers presented a completely amorphous microstructure at below $1,500^{\circ} \mathrm{C}$, thus the ability to retain an amorphous microstructure had little effect on the tensile strength at the temperature range of $1,300^{\circ} \mathrm{C}-1,500^{\circ} \mathrm{C}$. From the element analysis in Table 1, SiCN fibers showed a stable chemical composition after annealing at $1,400^{\circ} \mathrm{C}$ and a sharp decrease in nitrogen content when the annealing temperature reached up to above $1,500^{\circ} \mathrm{C}$, which agreed well with the relationship between the tensile strength and annealing temperatures. Thus, the decrease of tensile strength was mainly contributed to the carbothermal reduction of the $\mathrm{Si}_{3} \mathrm{~N}_{4}$ phase, which caused $\mathrm{N}_{2}$ gas release and formed defects in the fibers. On the contrary, the Young's modulus of SiCN fibers showed a slight increase as the annealing temperature increased, which may have contributed to the densification process under a high temperature. However, the Young's modulus of SiCN fibers presented a dramatic decrease before the full strength degradation, indicating that large amounts of pores or defects were formed due to the violent carbothermal reduction of the $\mathrm{Si}_{3} \mathrm{~N}_{4}$ phase.

\section{CONCLUSION}

In this work, the microstructural evolution, dielectric properties, EMW absorbing properties, and mechanical properties of SiCN

\section{REFERENCES}

Chen, Y., Yang, X., Cao, Y., Gan, Z., and An, L. (2014). Quantitative study on structural evolutions and associated energetics in polysilazane-derived amorphous silicon carbonitride ceramics. Acta Mater. 72, 22-31. doi:10. 1016/j.actamat.2014.03.049.

Ding, D., Zhou, W., Zhang, B., Luo, F., and Zhu, D. (2011). Complex permittivity and microwave absorbing properties of SiC fiber woven fabrics. J. Mater. Sci. 46 (8), 2709-2714. doi:10.1007/s10853-010-5140-x. fibers after annealing at a temperature range of $1,300^{\circ} \mathrm{C}-1,600^{\circ} \mathrm{C}$ were studied. SiCN fibers could retain their stable chemical composition at below $1,400^{\circ} \mathrm{C}$ and presented a dramatic decrease of nitrogen content due to the carbothermal reduction of the amorphous $\mathrm{Si}_{3} \mathrm{~N}_{4}$ phase when the annealing temperature went up to above $1,500^{\circ} \mathrm{C}$. Meanwhile, the amorphous free carbon graphitized at a temperature of $1,300^{\circ} \mathrm{C}-1,400^{\circ} \mathrm{C}$ and showed a $2 \mathrm{D}$ grain growth process at a temperature range of $1,400^{\circ} \mathrm{C}-1,600^{\circ} \mathrm{C}$. Due to formation and growth of turbostratic graphite carbon, the dielectric properties and EMW absorbing properties could be tuned by the heat treatment at different high temperatures. The minimum RL value was $-55.8 \mathrm{~dB}$ and the $\mathrm{EAB}$ value was $2.5 \mathrm{GHz}$ when the annealing temperature was $1,500^{\circ} \mathrm{C}$. The excellent EMW absorbing properties should have contributed to the formation and growth of grain boundaries and defects among the amorphous fiber matrix and turbostratic graphite carbon, which could enhance the space charge polarization at the heterogeneous interface and increase the conductivity of the SiCN fibers. Meanwhile, the SiCN fibers retained a rather high tensile strength of $\sim 1.0 \mathrm{GPa}$ after annealing at $1,500^{\circ} \mathrm{C}$, which confirmed them as promising candidates for reinforcing the stealth ceramic matrix composites used in harsh environments.

\section{DATA AVAILABILITY STATEMENT}

The raw data supporting the conclusions of this article will be made available by the authors, without undue reservation.

\section{AUTHOR CONTRIBUTIONS}

$\mathrm{XL}$ and SZ wrote the manuscript; CS and YW revised and analyzed the microstructural evolution of SiCN fibers; BW analyzed the EMW absorbing properties of SiCN fibers.

\section{FUNDING}

This work is supported by the National Natural Science Foundation of China (51203184, 51872329), the Aid Program for Science and Technology Innovative Research Team in Higher Educational Institutions of Hunan Province, and the Aid Program for Innovative Group of National University of Defense Technology.

Duan, W., Yin, X., Li, Q., Schlier, L., Greil, P., and Travitzky, N. (2016). A review of absorption properties in silicon-based polymer derived ceramics. J. Eur. Ceram. Soc. 36 (15), 3681-3689. doi:10.1016/j.jeurceramsoc.2016.02.002.

Gian, D. S., Tavonatti, C., Kundanati, L., Pugno, N., and Biesuz, M. (2020). Effect of the pyrolysis atmosphere on the mechanical properties of polymer derived SiOC and SiCN. J. Am. Ceram. Soc. 103 (11), 6519-6530. doi:10.1111/jace.17392

Li, Y., Liu, X., Nie, X., Yang, W., Wang, Y., Yu, R., et al. (2019). Multifunctional organic-inorganic hybrid aerogel for self-cleaning, heat-insulating, and highly efficient microwave absorbing material. Adv. Funct. Mater. 29 (10), 1807624. doi:10.1002/adfm.201807624. 
Liu, X., Yu, Z., Ishikawa, R., Chen, L., Liu, X., Yin, X., et al. (2017a). Single-sourceprecursor derived RGO/CNTs-SiCN ceramic nanocomposite with ultra-high electromagnetic shielding effectiveness. Acta Mater. 130, 83-93. doi:10.1016/j. actamat.2017.03.031.

Liu, X., Yu, Z., Ishikawa, R., Chen, L., Yin, X., Ikuhara, Y., et al. (2017b). Singlesource-precursor synthesis and electromagnetic properties of novel RGO-SiCN ceramic nanocomposites. J. Mater. Chem. C 5 (31), 7950-7960. doi:10.1039/ c7tc00395a.

Long, X., Shao, C., and Wang, J. (2019a). Continuous SiCN fibers with interfacial $\mathrm{SiC}_{\mathrm{x}} \mathrm{N}_{\mathrm{y}}$ phase as structural materials for electromagnetic absorbing applications. ACS Appl. Mater. Interfaces 11 (25), 22885-22894. doi:10.1021/ acsami.9b06819.

Long, X., Shao, C., Wang, S. S., and Wang, J. (2019b). Nanochannel diffusioncontrolled nitridation of polycarbosilanes for diversified SiCN fibers with interfacial gradient- $\mathrm{SiC}_{\mathrm{x}} \mathrm{N}_{\mathrm{y}}$ phase and enhanced high-temperature stability. ACS Appl. Mater. Interfaces 11 (13), 12993-13002. doi:10.1021/acsami. $9 \mathrm{~b} 00828$.

Mera, G., Riedel, R., Poli, F., and Müller, K. (2009). Carbon-rich SiCN ceramics derived from phenyl-containing poly (silylcarbodiimides). J. Eur. Ceram. Soc. 29 (13), 2873-2883. doi:10.1016/j.jeurceramsoc.2009.03.026.

Mo, R., Yin, X., Ye, F., Liu, X., Cheng, L., and Zhang, L. (2017). Mechanical and microwave absorbing properties of Tyranno®ZMI fiber annealed at elevated temperatures. Ceram. Int. 43 (12), 8922-8931. doi:10.1016/j.ceramint.2017.04.030.

Prasad, R. M., Mera, G., Morita, K., Müller, M., Kleebe, H.-J., Gurlo, A., et al. (2012). Thermal decomposition of carbon-rich polymer-derived silicon carbonitrides leading to ceramics with high specific surface area and tunable micro-and mesoporosity. J. Eur. Ceram. Soc. 32 (2), 477-484. doi:10.1016/j. jeurceramsoc.2011.08.020.

Sarkar, S., Gan, Z., An, L., and Zhai, L. (2011). Structural evolution of polymerderived amorphous SiBCN ceramics at high temperature. J. Phys. Chem. C 115 (50), 24993-25000. doi:10.1021/jp203287h.
Storch, M., Vrankovic, D., Graczyk-Zajac, M., and Riedel, R. (2018). The influence of pyrolysis temperature on the electrochemical behavior of porous carbon-rich SiCN polymer-derived ceramics. Solid State Ionics 315, 59-64. doi:10.1016/j.ssi. 2017.11.032.

Widgeon, S., Mera, G., Gao, Y., Stoyanov, E., Sen, S., Navrotsky, A., et al. (2012). Nanostructure and energetics of carbon-rich $\mathrm{SiCN}$ ceramics derived from polysilylcarbodiimides: role of the nanodomain interfaces. Chem. Mater. 24, 1181-1191. doi: $10.1021 / \mathrm{cm} 2038238$.

Ye, F., Zhang, L., Yin, X., Zhang, Y., Kong, L., Li, Q., et al. (2013). Dielectric and EMW absorbing properties of PDCs-SiBCN annealed at different temperatures. J. Eur. Ceram. Soc. 33 (8), 1469-1477. doi:10.1016/j.jeurceramsoc.2013.01.006.

Zhao, B., Guo, X., Zhao, W., Deng, J., Shao, G., Fan, B., et al. (2016). Yolk-shell Ni@ $\mathrm{SnO}_{2}$ composites with a designable interspace to improve the electromagnetic wave absorption properties. ACS Appl. Mater. Interfaces 8 (42), 28917-28925. doi:10.1021/acsami.6b10886.

Zickler, G. A., Smarsly, B., Gierlinger, N., Peterlik, H., and Paris, O. (2006). A reconsideration of the relationship between the crystallite size $\mathrm{L}_{\mathrm{a}}$ of carbons determined by X-ray diffraction and Raman spectroscopy. Carbon 44 (15), 3239-3246. doi:10.1016/j.carbon.2006.06.029.

Conflict of Interest: The authors declare that the research was conducted in the absence of any commercial or financial relationships that could be construed as a potential conflict of interest.

Copyright (c) 2020 Long, Zhang, Shao, Wang and Wang. This is an open-access article distributed under the terms of the Creative Commons Attribution License (CC $B Y)$. The use, distribution or reproduction in other forums is permitted, provided the original author(s) and the copyright owner(s) are credited and that the original publication in this journal is cited, in accordance with accepted academic practice. No use, distribution or reproduction is permitted which does not comply with these terms. 